\title{
NATURE-INSPIRED ARCHITECTURE OF LAURIE BAKER AND TOYO ITO: A COMPARISON
}

\author{
ANJALI SADANAND ${ }^{1} \&$ RAMASAMY VEERANASAMY NAGARAJAN ${ }^{2}$ \\ ${ }^{1}$ Measi Academy of Architecture, India \\ ${ }^{2}$ Hindustan Institute of Technology \& Science, India
}

\begin{abstract}
Architects dialogue with "nature" in different ways. To some, nature is considered part of architectural space and to some separate but crafted to give the illusion of a continuum. For both, nature inspires and the actual interface with nature determines their architecture. An enquiry based on the manner of this interface is the basis of this paper. The objective is to investigate what prompts an architect to construct this interface and how it impacts architecture. The expression of this interface in terms of elements of architecture and resulting form, space, structure and material will be explored in this paper, through a discussion based on a comparison between the works of two architects, Laurie Baker and Toyo Ito. Simon Unwin's elements of architecture will be used to construct a theoretical framework for architectural elements and Heidegger's theory on "place" will provide a phenomenological base of enquiry. This will be illustrated in terms of architectural precepts and expression in the architecture of Laurie Baker and Toyo Ito with respect to the formalizing of form and structure. Buildings of both architects will be analysed with respect to their connection with nature. Comparative discussion of five projects of each architect in their respective treatment of architectural elements such as material, roof, and wall and structure and skin will demonstrate the language of each architect in its mode of translating nature into architecture. The paper will suggest that culture as in beliefs, through religion influence architectural thought and has brought out a diversity in approach seen in the work of these two architects which has in turn been tempered by local traditions and context.
\end{abstract}

Keywords: nature, structure, form, brick, steel, place, wall, roof.

\section{INTRODUCTION}

Nature present in natural surroundings and in its elemental form in trees, ponds, rocks etc; have been a source for inspiration for centuries to architects. In some cultures nature is considered sacred and revered. Japanese construction tradition was greatly influenced by the country's two main religions: Buddhism and Shintoism [1]. Shintoism is a native Japanese religion which is based on nature worship. Shintoism triggered the Japanese interest in worshipping nature and Buddhism perpetuated the Zen aesthetic of "nothingness". "This simple concept of nothingness gave birth to the idea of the Zen aesthetic and of places dedicated to contemplation" [1]. The spirit of Zen is expressed in a minimalistic aesthetic. The significance of the Japanese house is "its aestheticism of simplicity and restraint stands out against the modern simplicity brought about by economization and mechanization of building" [2]. Japanese houses have a distinct relationship with the garden and inside and outside space are considered one. Internal spaces are flexible and views to the exterior are controlled by movable screens (Fig. 1). "The oldest tradition of all is that the garden represents nature since pre-historic times and had been regarded as sacred. This is true for both Shinto and Buddhism" [3].

Vernacular architecture in Kerala like other parts of India was the result of a process of responding to the environment. Architectural forms corresponded to climatic conditions and were made of locally available material such as wood, laterite stone and mud. Age old texts dictated rules, proportions and materials and construction methods for buildings. In Kerala 


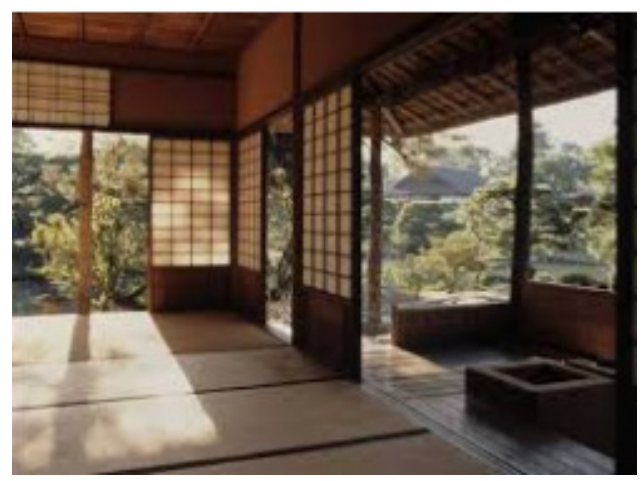

Figure 1: Japanese interior showing screens. (Source: EastAsiaarchitecture.org.)

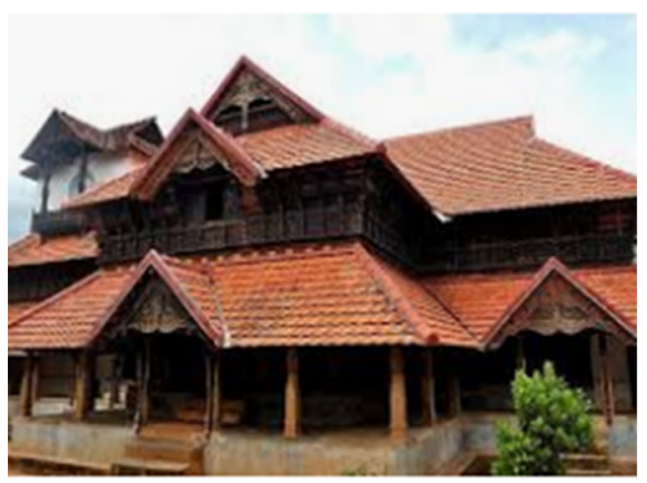

Figure 2: Kerala traditional architecture. (Source: Pinterest.)

houses were designed around courtyards which facilitated air movement, brought light and gave privacy to women's areas in the house. As Kerala is in a tropical hot and humid zone with excessive rainfall, roofs are sloped and houses had openings in walls to perpetuate air movement. Clay tile roofs give thermal protection at the roof level. (Fig. 2) Japan has a multitude of seasons whereas Kerala has year round uniformly hot humid climate with few months of a rainy season. Architecture is designed to keep out the heat by shading the building through roof overhangs and to withstand heavy rainfall by its deep slope roofs. Laurie Baker has taken the essence of the vernacular into his buildings in new interpretations in brick and stone. "An old tree and an awkward slope are reconciled in a composite solution, that Baker's works achieves a set of earthy on-site lyricism" [4]. Baker accommodates awkwardness in site situations into his buildings as though they were part of the design which give a sense of naturalness. Baker's work is on-site and his solutions come from the site. Basic drawings are prepared and frequent on site decisions enhance the building. "During construction, if he believed that a small window would give someone in the kitchen a view of a beautiful tree, a window was duly put in" [4]. The inclusion of nature as part of the architectural experience was essential to him. Toyo Ito's design process is in reverse, as he works on abstract ideas and concepts inspired from nature. His fascination with trees has resulted in many interesting buildings which use the shape of a tree as its base form for structure. A comparison between the two architects will show their differences in architectural style and process but will also show their similarity in striving for simple solutions and a constant direction to accept an engagement with nature as significant to their design objective. It will be shown that religion shapes their perception in making design decisions. Through different approaches both attempt to create architecture which reconciles with nature.

\section{THEORETICAL FRAMEWORK}

German philosopher Martin Heidegger's seminal text "Building Dwelling Thinking" was published in 1954 (English 1971). Heidegger defines "to dwell" not as a mere activity or to take shelter but in the context of tradition, time and memory and associated nuances of the senses which make that activity meaningful. He defines "to dwell" as the way in which humans are on the earth. The general he says is visible in the local in a concretized form. He also calls what is between the earth and sky the "world" and comments that the world as he 
defines it, is "the house" where mortals live. "In general nature forms an extended comprehensive totality a 'place', which according to local circumstances has a particular identity" [5]. Place is distinguished from space. What is felt in the present is significant. Space can be said to be created before it is experienced.

Simon Unwin in "Analysing Architecture" talks about elements of architecture as the column, the wall and roof. He comments on their purpose and role they play in architecture in terms of structure, aesthetics, creating a sense of identity etc; Elements can play diverse roles in one single building. In "The Wall" Simon Unwin talks in detail about the wall as a form of enclosure, a marker and a structural support. In addition he talks about "the inhabited wall" where the wall through its depth houses rooms. A linear line of rooms can be considered as a single wall of thickness where the space is occupied by rooms. Unwin's elements give a framework of components by which the projects of Toyo Ito and Laurie Baker can be compared.

\section{METHODOLOGY}

Five examples of buildings from Baker and Ito will be analysed in context of a set of parameters to describe their architectural characteristics in terms of the way in which the buildings harmonise with nature.

Parameters of study:

1. Elements

2. Inside-outside interface

3. Light and shadows

4. Shape and form

5. Creation of a Sense of place

6. Material

\section{INFLUENCES AND PHILOSOPHY}

Toyo Ito is a Japanese Architect who won the Pritzker Prize in 2013.He was born in 1941 in Korea but later moved with his family to Japan. In his youth he was exposed to architecture by his parents. His father drew house plans for friends and his mother hired an early Modernist Architect Yoshinobu Ashihara, "who had just returned to Japan from the U.S. where he worked at Marcel Breuer's office, to design their home in Tokyo" [6]. Toyo Ito began working in the firm of Kiyonori Kikutake and Associates after graduating from Tokyo University's Department of Architecture in 1965. In 1971, he founded his own studio in Tokyo, and named it initially Urban Robot (Urbot) which he changed in 1979 to Toyo Ito and Associates. Toyo Ito's architecture can be divided into two phases, an earlier Modernist influenced phase and a later phase after the design of his watershed building Sendai Mediatheque. The Pritzker citation commented that "Toyo Ito has been able to produce a body of work that combines conceptual innovation with superbly executed buildings" [7]. Toyo Ito works with materials like concrete, glass, steel and aluminum. He explores their potential as materials attempting to push boundaries with technical innovations within the framework of design and structure. Each project is handled individually, as responds to site and the specific nature of its inhabitants.

Laurie Baker (1917-2007) was born Laurence Wilfred Baker in Birmingham, England where he graduated to become an architect. "A pacifist - Baker became a Quaker in his teens - and a conscientious objector, he was sent to southern China as a trained paramedic with the Friends Ambulance Unit in late 1941" [8]. He did voluntary work in several leper colonies all over the world including China. On his way back to England in 1944 he met Mahatma Gandhi who made a deep impression on him. He returned to work in India for the Mission to 
Lepers or The Leprosy Mission as it is currently known. In Faizabad he met a Doctor whom he married and the couple set up a hospital in Pithoragarh. In 1961, the couple moved to Kerala and eventually to Trivandrum where he built his house The Hamlet and started practicing architecture. "The root cause for his unique outlook on life was, undoubtedly the acceptance of the Quaker philosophy" [9]. "Baker's architecture, firmly anchored to his Quaker beliefs, is ordered by considerations and circumstances of this ancient ecclesiastical consciousness. To enter a room, a hall, a house built by him is to become immediately aware of this profound connection" [4]. Baker's personal accord with a way of life and a way of work invests his buildings with the values he cherishes. In designing objects finely constructed and complete in themselves, there is a reflection of Baker's intensely realized faith, his unusual set of principles imbibed from the law of customs of his religious sect. "This attitude to life and work is so deeply rooted in this distinct philosophy that it has established - even amongst people of different faiths - a unique architectural tradition" [9]. Baker's meeting with Gandhiji had a strong impact. Baker started implementing Gandhiji's conviction that rural buildings should be built with material available within a 5 mile radius and discovered by building all over India that Gandhiji was right. Baker's approach was based on necessity as the basis. He called his approach "cost effective" as opposed to "low cost". "He spoke of a common sense, context specific, low waste, resource management approach in all stages of design and construction. He advocated the use of energy efficient material, especially renewable and reusable ones and locally available materials" [9]. "During construction, if he believed that a small window would give someone in the kitchen a view of a beautiful tree, a window was duly put in" [8]. "In a critical sense, he was perhaps the most substantive minimalist among modern architects anywhere. His architecture maximised sensuousness and a rare depth of habitational experience while minimising material and fossil energy consumption, thereby cutting costs significantly" [4]. He used shapes literally from nature as in the mango, a favourite of his in tile patterns and as a courtyard in a house Trivandrum.

\section{ELEMENTS}

Columns for Toyo Ito are significant and embodied with cultural significance taken from his early work experience with Kiyonori Kikutake. In an interview with for Architectural review he comments "An observation by Kikutake is very important to me, columns set off space, floor defines space. The columns are like trees, which initiate space and emanate energy" [6]. "There is also a parallel between Kikutake's observation and the 'Onbashira' - a festival celebrated in Nagano, where I grew up. There's a shrine called Suwa Taisha, and around it are four wooden pillars that define the sacred space. The Onbashira is a celebration that takes place every six years when those pillars are renewed. The people of the village go to the mountains and chop down four huge trees with traditional tools. According to traditional Japanese beliefs, deities reside in those four trees and in the pillars. The trunks are renewed to" [6]. Ito's importance to trees as inspiration is further seen in the design for the Sendai Mediatheque. He conceptualized a building as a box standing on 6 columns which came from an image of seaweed in water. The seaweed like columns suggested that nature was the inspiration. According to Ito the space in Sendai Mediatheque is akin to a forest where the spatial quality of spaces are diverse and not homogenous. To Ito, the mesh of tubes produced by welding steel pipes is reminiscent of trees and echoes the line of zelkova trees in front of the building. Ito describes space in Sendai Mediatheque as a "layered urban forest" (Fig. 3). Ito uses nature to evoke design responses in an abstract sense that are conceptualized and translated into building elements and add value to the aesthetics of his architecture. In the "U" shaped house, described below, Toyo Ito creates a concrete wall that shuts out the outside 


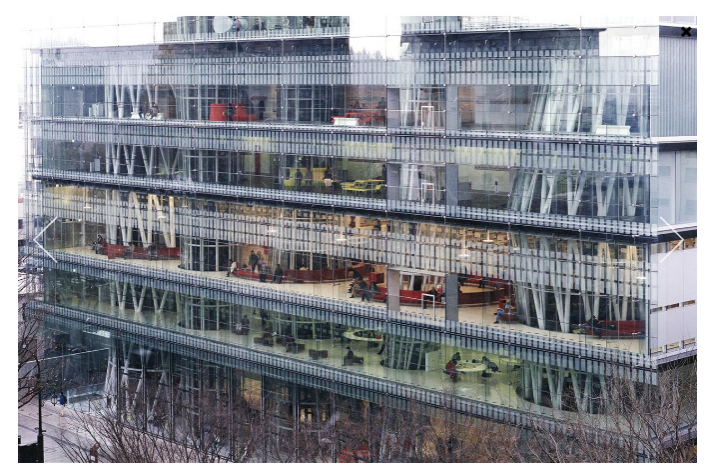

Figure 3: Sendai Mediatheque. (Source: Pritzker.)

world but carves out a private space that creates an internal link to nature. Baker takes available resources to see what best he can do with them in that a building element has multiple roles to play.

Baker re-interpreted building elements of the vernacular into cost effective solutions using traditional concepts of ventilation with new low cost technological innovations. The courtyard as a spatial element and the jalli wall are significant elements derived from the vernacular and the "jalli" and exhibit his philosophy. The courtyard is a traditional element found in Kerala houses used primarily to ventilate and bring in light. Baker used the courtyard as an element which unified the building to nature and spatially organized the building giving it in addition light and ventilation. The courtyard was often articulated with a tree or decorative pool which further enhanced the connection to nature. Gautam Bhatia comments "the need for contact with the outside and with the organic profile of the site leads Baker to introduce architectural elements that express this duality of inside and out, man-made and natural" [4]. In the Vaidyanathan House (Fig. 4) located near paddy fields, an open to sky courtyard is a significant feature "completing the inner wall of the house in a pattern of staggered brick and becoming the home of an ancient mango tree" [4]. To keep the houses ventilated and climatically comfortable, houses in Kerala often built of timber have narrow apertures in the woodwork of their walls in the form of slats or pierced sections that facilitate air movement. Baker interpreted these features in the brickwork where through the manner in which brick was laid apertures formed permitted light and air movement. These walls were called "jalli" walls. The entrance door is located such that one walks along the curve of the circular wall into garden space and "once inside the focus shifts away from the centre....to the outward curving walls and the paddy fields beyond" [4]. Baker has designed the house with nature as a component present in the tree and courtyard and as the context. The house "breathes" nature through its apertures in the brick wall and its orientation. The wall is instrumental in creating this interface through its permeability and degree of enclosure that it creates. The house is built with the naturalness of the site unchanged. The courtyard and tree bring a sense of place to the house by creating an intimacy of space, context and memory. The jalli wall though its pattern affords privacy from the fields around as well as creates a backdrop for activities within and through its apertures a visual connection with the fields is maintained. Baker often repeated the use of the traditional sloped roofs but constructed in concrete and with terracotta fillers to make them lighter and more economical. He proposed the rat-trap bond which used less cement as an economical and sturdy alternative against the conventional brick wall. 

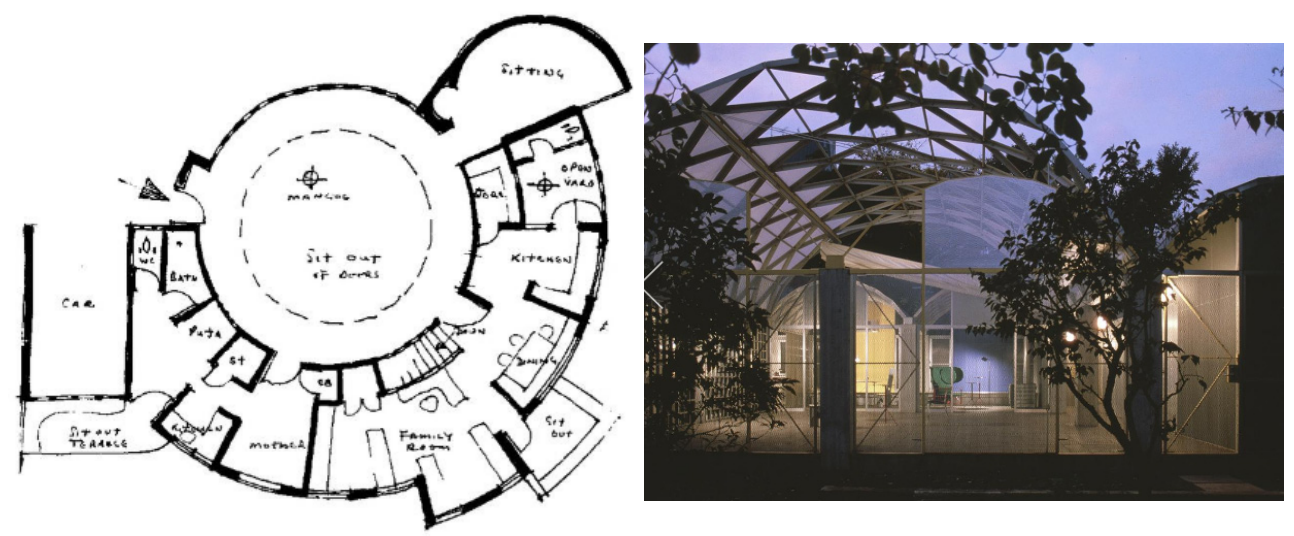

Figure 4: Plan of Vaidyanathan residence. Figure 5: The Silver Hut. (Source: (Source: Laurie Baker, Life, Pritzker Prize.) Works, Writing.)

\subsection{Inside-outside interface}

"Building and nature are two elements that traditional Japanese architecture regards as one" [1]. To each space, special attention is given to the placement of openings to view exterior spaces where views are captured through orchestrated movements of screens or judiciously placed openings. These views are framed views. In order to further understand Japanese traditional architecture, one important point to keep in mind is the importance given to interior and exterior space. Both are seen as one, an ambiguous space created by blurred boundaries. Toyo Ito interprets in his contemporary architecture these two aspects of traditional design of interior and exterior space as one and framing of views in the Silver Hut and the "U" house. Toyo Ito built the Silver Hut as his own residence in 1984 in Tokyo. He incorporated the Japanese concept of flexibility in traditional homes and unity with landscape by creating an area in the city which was protected and where a courtyard space, which was a garden space, was created, similar to the space "enclosed by draperies" in the traditional sense and where spaces in the house merged into this open space. "In the Silver Hut, the overall volume is broken down into a series of vaulted roofs formed by a reticular structure of steel, always left visible" [7]. The roof plays a significant role in creating differential volumes of space where the covering is either open or solid, transparent or opaque. "The courtyard garden and the distribution of volumes ambiguously compromise any distinction between interiors and exteriors and create a single and constant fluid space, rendered dynamic by the series of roofing vaults" [7].

Patterns in light patches are created by the collage of different situations in the covering of the steel roof. "The central area has the longest spanning arches and serves as an outdoor retreat. These braced arches create a pattern of triangles, some being transparent while others have a taught, light skin stretched over them to block some of the light (Fig. 5). The arches throughout the rest of the house are mostly covered, but there are a few triangles that allow light to pass through" [10]. Ito uses the concept of de-composition to fragment the house into different elements in order to transfer it into an abstract entity. "It incorporates perforated and transparent screens that give a contemporary twist. Ito viewed perforated aluminum as 
having the same capabilities and effects as paper screens and movable walls, which are typical Japanese design techniques" [10].

In Lt General Pillai's house (Fig. 6) Baker uses the entire site to spread out the residence. The design of the house is constituted by the inside-outside interface. The house is built for two families. The plan spreads out in wings to cover almost the entire site. Baker uses the garden as his main focus in terms of circulation in the form of jalli enclosed corridors that give fragmented views of the garden and the Principal rooms which are designed like pavilions surrounded by garden on three sides. Exposed brick forms his material palette. Sense of place is created by the characteristics of the area of the garden you are located in.

Flexibility and change accommodated by screen walls and articulated by the subtle difference in the architectural character of spatial volumes describe Toyo Ito's response to the interior exterior interface which arise from the notion of the perception of the interior and exterior as one space as in Japanese thought. Boundaries are blurred. Baker on the other hand uses a spread out plan with permeable walls that connect visually at all times with the exterior as you traverse the house and make you feel always part of the exterior but sheltered as exterior and exterior are two separate entities which are visually connected by the openings in the wall. A sense of place is always maintained through defined stops in the landscape where each space has a significance. Unlike in Ito's case one interfaces with individual spaces and not a section of carved out landscape as a whole.
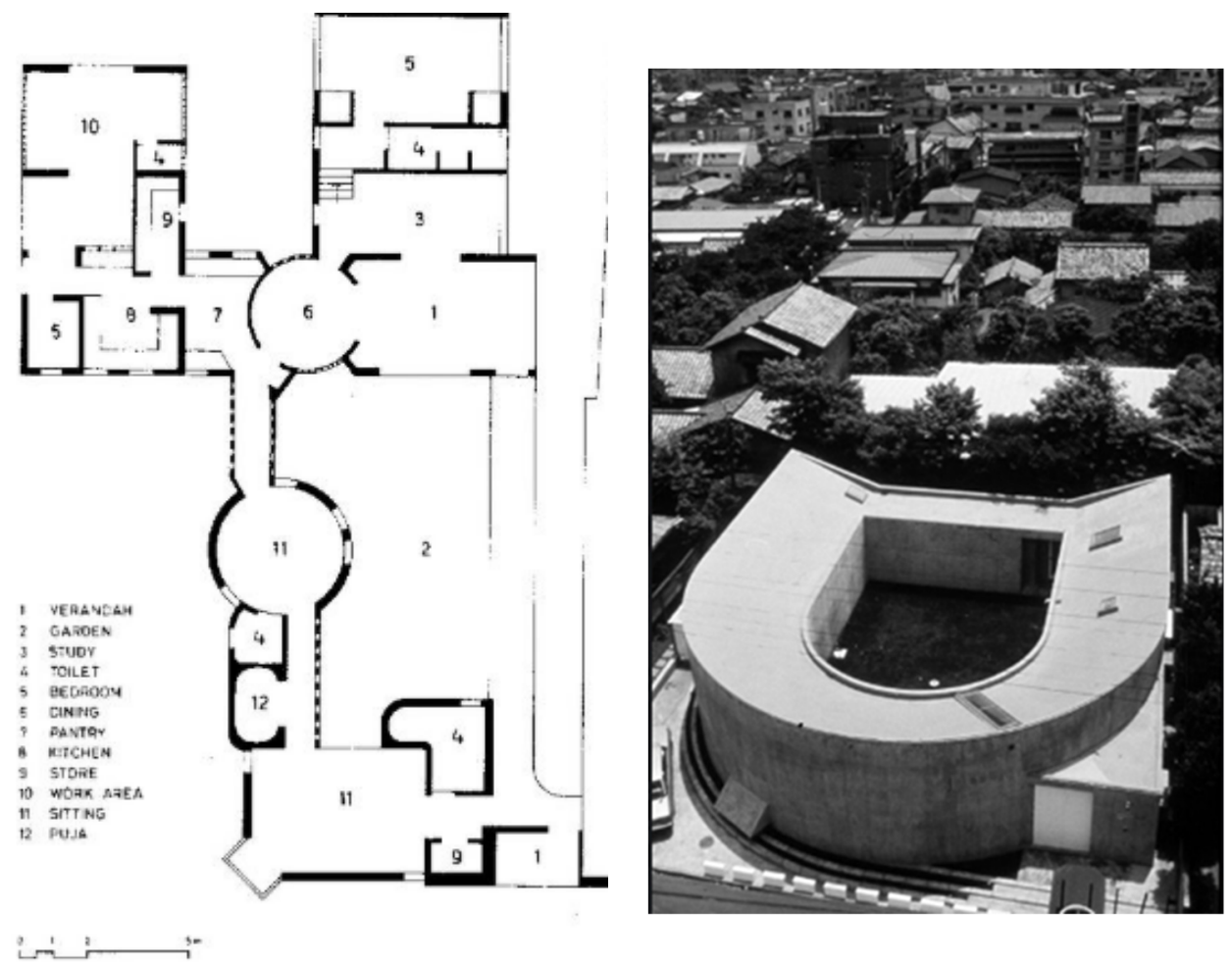

Figure 6: Plan of Lt General Pillai's house. Figure 7: The "U" House. (Source: Pritzker.) 


\subsection{Shape and form}

The white U house, (Fig. 7) one of Toyo Ito's earlier projects, was built in 1977, for his sister who had just lost her husband. Ito conceptualized a place to help her heal and the house consists of a ring like a "U" which encloses an open space. The house is inward looking (Fig. 8), and focuses on the interior courtyard. An impregnable white concrete wall separates the outside world and creates a stillness within. Interior rooms look on to a central open space. Windows or openings near the ceiling let light in and the wall functions as a hard boundary enclosing the central space conceived as a garden of contemplation for his sister who had just lost her husband. Simplicity is the key concept here echoed in the architect's use of the simple surfaces covered in white plaster. "The inner courtyard is covered with beaten earth as if it were a natural desert without any vegetation to compromise its decorative form" [7]. Ito sometimes speaks of it as a "garden of light" created between two "U" shaped walls. Lighting is soft in the interior and in contrast with the light in the courtyard. There are no windows on the exterior wall at eye level. The wall is envisaged as the screen or "drapery" which shuts off the outside and locally connects internal spaces to the courtyard. In Simon Unwin's definition of "walls" the house can be described as a "u" shaped inhabited wall. The roof slab slopes to the centre and light enters from the top and at the ends where roof meets wall. Toyo Ito comments "We must recover an intimate relationship with the natural environment and locally connects internal spaces to the courtyard. Human beings were once a part of nature and so was architecture. Is it possible to recover the understanding of architecture as part of nature" [6].

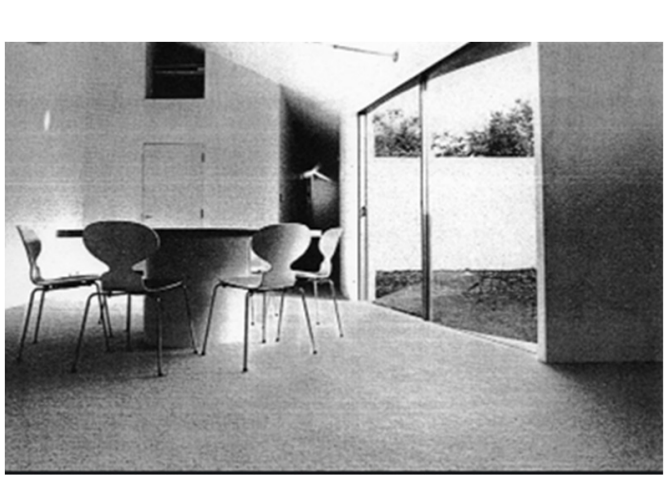

Figure 8: Interior of the "U" House Silver Hut. (Source: Pritzker.)

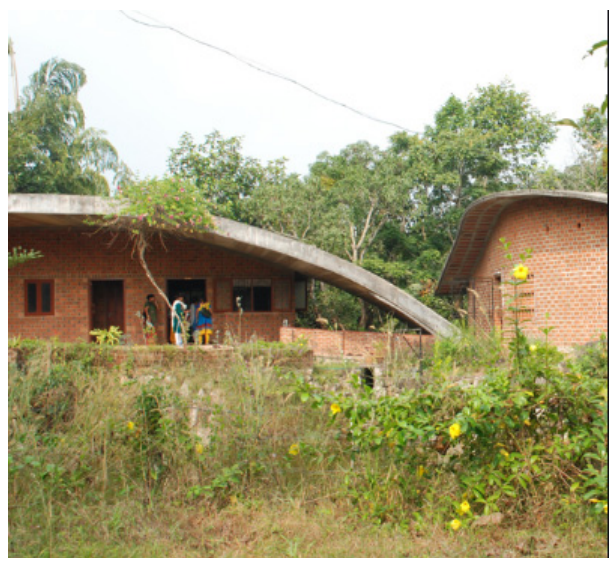

Figure 9: SEWA building. (Source: Laurie Baker Centre.)

In an interview Ito comments "I recall how Japanese people celebrated the cherry blossom season in former times. They went into a park, into nature, and separated a certain area underneath the trees with draperies. By doing nothing more than that, they created a special place" [6]. Traditional wooden residential architecture retained a variation of different spaces within it and created an intimate relationship between nature and people, where differences in the spaces were felt through the five senses. The courtyard in both instances evokes a sense of place by engaging the senses, either in contemplation as in the U house or by meaning given to through social engagement in the Silver Hut. In the house for $\mathrm{R}$ 
Narayanan Baker designed the house around a mango shaped courtyard with a coconut tree in the centre. Designed for a dancer it performs as an interaction space. The jalli wall connects the interior to the courtyard visually. The SEWA building (Fig. 9) in the Laurie Baker Centre campus features an organic shaped roof that blends with the surrounding terrain which is sloped and heavily vegetated with trees. Curved walls and curved roof echo nature's form in Baker's buildings such that the building nestles effortlessly in the landscape. The roof is made of the filler slab, Bakers cost-effective solution for roofing. A large shaded veranda is located at the front like all traditional houses which is a social space and a thermal buffer to the interior. Baker's curved walls are not purely aesthetic but as a solution to give extra stability in brick construction. Baker's buildings are largely of load bearing brick construction.

\subsection{Structure}

Trees provided an inspiration for Toyo Ito for the design of a building for TOD (Fig. 10) an Italian shoes and handbag company in a fashionable part of Tokyo called Omotesando. Ito's office provided the description as follows. "Trees are natural objects that stand by themselves and their shape has an inherent structural rationality". The pattern of overlapping tree silhouettes also generates a rational flow of forces. Having adapted the branched tree diagram the higher up the building, the thinner and more numerous the branches become, with a higher ratio of openings. "Similarly, the building unfolds as interior spaces with slightly different atmospheres relating to the various intended uses" [11]. Ito talks about trees and their importance to him in inspiring design solutions.

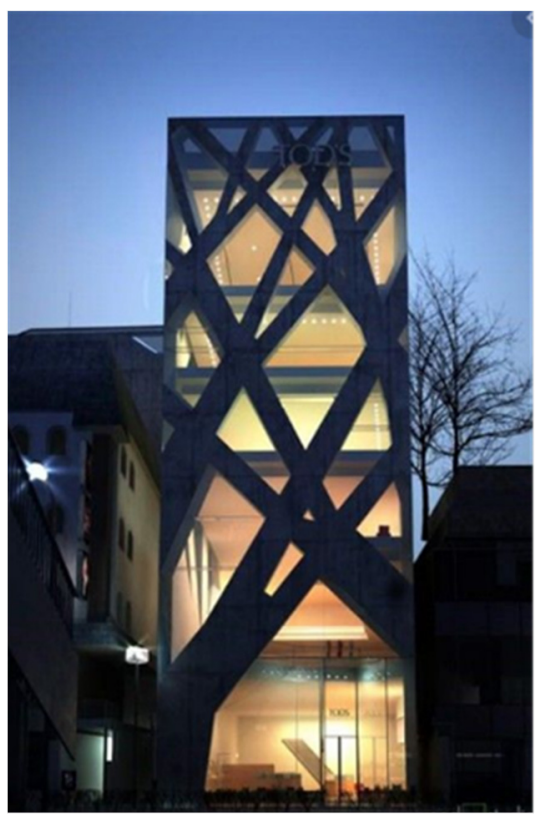

Figure 10: TOD. (Source: Pritzker.)

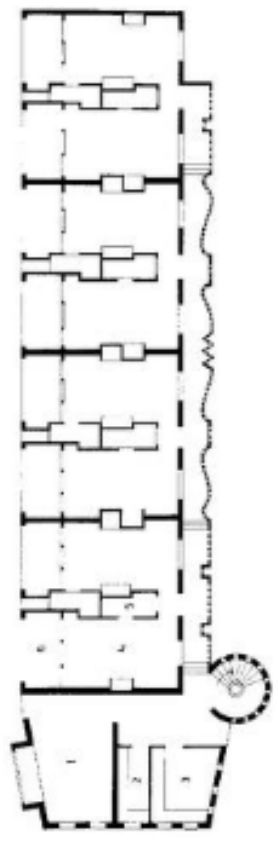

Figure 11: Men's Hostel plan. (Source: Gautam Bhatia, "Laurie Baker, Life, Work, Writings".) 
"Living organisms he says have an inbuilt order as their most prominent characteristic. This order is prevalent in trees as being dynamic in the form of repeated self-organization seen in the structure of their limbs" [11]. The concrete walls in the TOD building are like wrapping paper that wrap around the building also fulfilling a structural requisite.

Baker has devised the use of the articulated wall as a cost effective structural strategy for buildingwhich through its semi transparency of jalli opennings maintains connection with site and environment. Baker's solutions are in addition climate responsive. The Centre for Development Studies by Baker in Trivandrum consists of a campus of several buildings scattered on an uneven sloped site. Each building has been carefully designed to fit with its natural site condition and "each in its own landscape, created by groves of existing trees and foliage" [4]. Buildings take their shape from their location. The height of the coconut palm determines the heights of traditional buildings in Kerala and Baker has followed this rule. In the Men's hostel (Fig. 11) at the Centre, eight rooms on one floor in a linear line have access to a connecting corridor where Baker has used an undulating single brick jalli wall that responds visually to the organic shapes found in nature and structurally allows for more stability. The walls are Jalli walls which afford privacy and light and ventilation. Patterns are created on the floor by the light which falls in patches stimulating interest and creating a sense of place (Fig. 12).

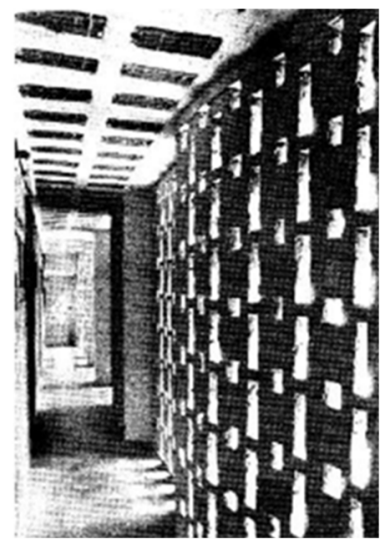

Figure 12: Light patterns in Men's Hostel. (Source: Laurie Baker, Life, Works, Writing.)

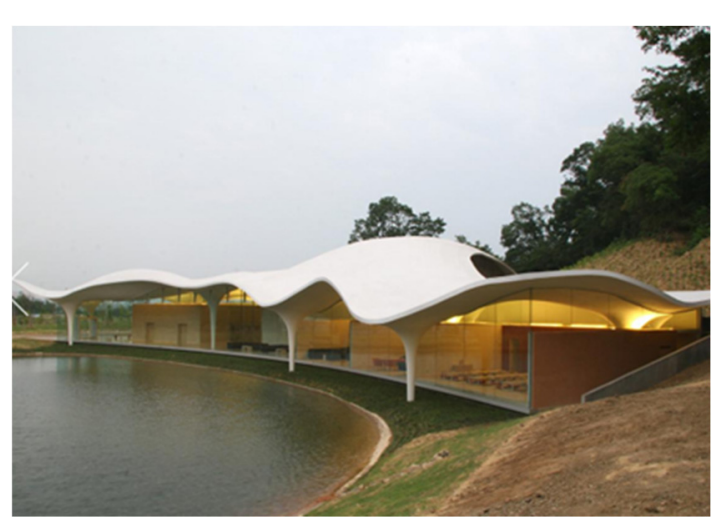

Figure 13: Meiso No Mori Crematorium. (Source: Pritzker.)

\subsection{Sense of place}

In the Meiso No Mori Municipal Funeral Hall (Fig. 13) Ito has designed a structure which is a place of reflection and contemplation where the organic language of architecture brings nature closer. The undulating concrete shell roof and tree-like columns contribute to make the experience of this building poetic. Sense of place is achieved through the harmony of architecture and natural surroundings. "Developed in collaboration with engineer Mutsuro Sasaki, Ito's concept for the funeral hall was borne out of a desire to merge evocative symbolism with a logical structural rationale. The flowing plane of white concrete is 
reminiscent of the smoke that rises from the cremation furnaces, while also appearing as a part of the landscape, connecting ground, sky, lake and hill" [12]. The project architect, Leo Yokota, describes the guiding image: "Rather than the heavy, dignified architecture usual with crematoria, we imagined a soft place, as if a gentle snowfall had settled lightly upon the site to form a broad and generous roof' [12].

A health resort (Fig. 14) was proposed by The Then Chief Minister of Kerala in Ponmudi, on a hilly site $60 \mathrm{~km}$ away from Trivandrum. The site was strewn with rocks and boulders and was devoid of vegetation. Baker proposed a scheme of cottages using local materials of stone, whose simple geometric forms and sloped roofs appeared like abstractions of the rocky terrain and harmonized with them. Baker commented that he thought of them visually as scattered rocks that had fallen and were anchored to a cliff. Baker created a sense of place in the mountains by his proposal for the Tourist Centre. The buildings through their activity and community provided a place signified by their architectural character and embodied by time memory and tradition. A phenomenological experience is created in both architectural designs through their sensitivity to material and form, and response to nature.

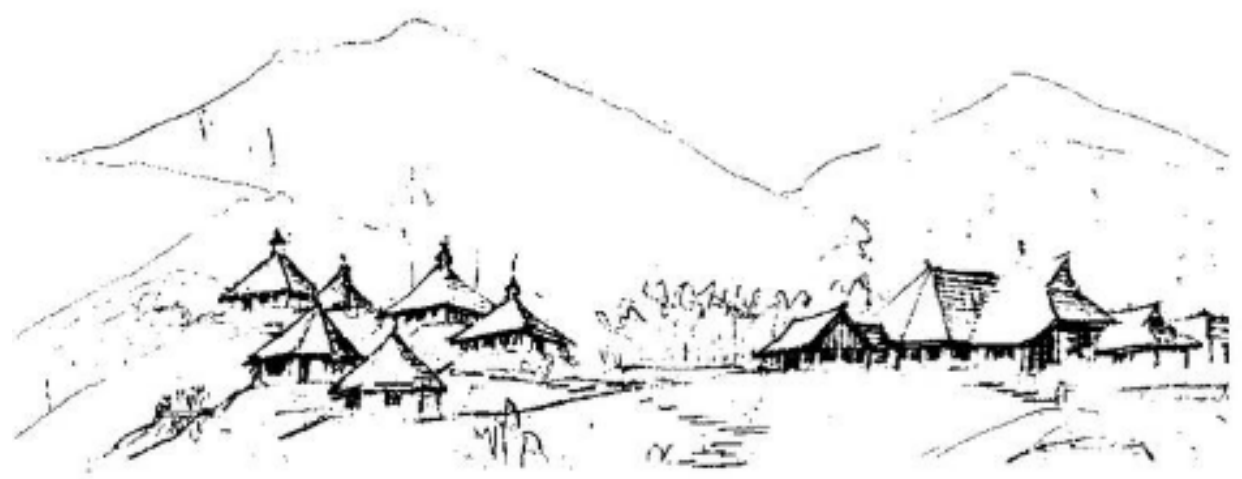

Figure 14: Ponmudi resort. (Source: Gautam Bhatia, “Laurie Baker, Life, Work, Writings”.)

\subsection{Materials}

Toyo Ito innovates in materials that can be used in construction to withstand earthquakes. Concrete, glass and steel and aluminum are the main materials he works with. Baker uses materials available within a 5 mile radius of the site. Baker uses low-technology and resources available in the area while Ito's structural designs and architectural projects involve high technological innovations and craft. His designs are simple but execution can be complicated and require expertise.

\section{FINDINGS AND CONCLUSION}

Hence it has been shown that both Baker and Toyo Ito though their respective architectural language of their buildings show their strong connect and desire to connect with nature. Their design processes are different and their objectives come from different sources. Baker comes from a Quaker approach that recognizes craft and attention to detail and believes that beauty comes from simplicity and order and seen in nature and in the belief that all things are God's objects. Toyo Ito comes from his early influences of Shintoism and Buddhism which ask for a simple solution which is nature inspired and minimalistic. 
Ito's sense of minimalism is in his aesthetic while Baker's sense of minimalism is in the economy with which he approaches all aspects of building and design. As shown in Table 1, both architects design for site specific conditions. Ito desires his buildings to humanize with nature and people and designs from a view of merging and blurring boundaries through transparency and lightness in his buildings. Tradition and culture motivate him and his work is a testimony to a continuous relationship with nature people and the environment. Nature inspires in conceptualization for multiple derivations from structure to form. Ito has commented that he looks at architecture as clothing, that wraps around people. Ito's architecture portends an architecture of diverse possibilities arising from a studied response to specific design criteria with a wide palette of materials and scope for new technology. Baker works with nature, its irregularities and characteristics to create buildings that harmonise with nature through optimization of natural materials and forms. Baker's thought process and buildings embody a sustainable way of looking at architecture. Notwithstanding that several of Ito's buildings are in the urban context they still connect in a figurative sense with nature in terms of elements such as trees etc. Baker is practical and craft based where the tectonic is the primary craft while Ito is intellectual and creative and responds through innovative abstract concepts and imagery. For Ito building elements are tools of expression playing out his concepts. For Baker building elements are the basic building blocks that form the spine of his building. Baker uses the materials found local to site and encourages local traditions modernized and made relevant to today's context. His design solutions are simple but his aesthetic allows for decoration as in the patterns of his jallis. Baker and Ito's buildings impact architecture in that they show ways of keeping culture and tradition alive by reinterpretation in contemporary methods and craft at the design and conceptual level as in

Table 1: Comparison of Toyo Ito and Laurie Baker.

\begin{tabular}{|l|l|l|}
\hline $\begin{array}{l}\text { Design } \\
\text { philosophy }\end{array}$ & $\begin{array}{l}\text { Toyo Ito } \\
\text { early Modernist background } \\
\text { and Zen Buddhism. }\end{array}$ & $\begin{array}{l}\text { Laurie Baker } \\
\text { Quaker principles of simplicity } \\
\text { and economy. }\end{array}$ \\
\hline Design approach & $\begin{array}{l}\text { Minimalism in design through } \\
\text { idea conceptualization. }\end{array}$ & $\begin{array}{l}\text { Minimalism in materials and } \\
\text { maximization of material and } \\
\text { building elements as the driving } \\
\text { force. }\end{array}$ \\
\hline Site & $\begin{array}{l}\text { Abstraction. } \\
\text { inhabitants needs. }\end{array}$ & $\begin{array}{l}\text { Design for site specific and } \\
\text { inhabitants needs. }\end{array}$ \\
\hline Nature & $\begin{array}{l}\text { Nature as perceived as sacred. } \\
\text { Interior-exterior }\end{array}$ & $\begin{array}{l}\text { Nature as part of other objects as } \\
\text { containing God. "God is in } \\
\text { everything". }\end{array}$ \\
\hline \multirow{2}{*}{ Elements } & $\begin{array}{l}\text { Walls become a skin, } \\
\text { connecting through aesthetics } \\
\text { to nature. }\end{array}$ & $\begin{array}{l}\text { Two separate entities } \\
\text { Light is an element in roof. } \\
\text { connect through materiality and } \\
\text { permeable to allow glimpses of } \\
\text { nature and create patterns of light. } \\
\text { Light is an element in walls. }\end{array}$ \\
\hline
\end{tabular}


the work of Ito and at the level of building craft innovation as in the work of Baker. This ensures identity of place and assures continuity with change. Both architects in their contributions to architecture create buildings that embody a specific "sense of space" through materiality and the phenomenological experience of their architectural spaces.

\section{REFERENCES}

[1] Garda, E., Mangosio, M. \& Pastore, L., Learning from the past: The lesson of the Japanese house. WIT Transactions on the Built Environment, vol. 171, WIT Press: Southampton and Boston, pp. 275-284, 2017.

[2] Engel, H., The Japanese House, Charles E. Tuttle: Japan, p. 24, 1983.

[3] Nose, M., The Modern Japanese Garden, Mitchell Beazley: London, p. 8, 2002.

[4] Bhatia, G., Laurie Baker, Life, Work, Writings, Penguin: India, p. 40, 2014.

[5] Schulz, N., Genius Loci: Towards a Phenomenology of Architecture, Academy Editions: London, p. 10, 1980.

[6] The Architectural Review, Interview: Toyo Ito. www.architectural-review.com/ essays/interview-toyo-ito/8644601.article. Accessed on: 27 Jan. 2020.

[7] Maffei, A., Toyo Ito: Works Projects Writing, Phaison Press: Milan, pp. 10-12, 2002.

[8] The Architectural Review, Laurie Baker (1917-2007). www.architecturalreview.com/essays/reputations/laurie-baker-1917-2007/10045413.article. Accessed on: 27 Jan. 2020.

[9] Kannan, K.P. ed., Kerala in Transition, Laurie Baker Centre for Habitat Studies: India, p. 89, 2018.

[10] Arch Daily, www.archdaily.com/345849/ad-classics-silver-hut-toyo-ito. Accessed on: 27 Jan. 2020.

[11] The Pritzker Architecture Prize, www.pritzkerprize.com/laureates/2013. Accessed on: 27 Jan. 2020.

[12] The Plan, Meiso no mori municipal funeral hall. www.theplan.it/eng/magazine/theplan-027-06-2008/meiso-no-mori-municipal-funeral-hall. 